Rev. Bras. Saúde Prod. Anim., Salvador, v.13, n.1, p.204-213 jan/mar, 2012 http://www.rbspa.ufba.br ISSN 15199940

\title{
Exigências de cálcio e de fósforo disponível para codornas japonesas de 26 a 38 semanas de idade
}

\author{
Requirements for calcium and phosphorus available for Japanese quail of the 26 to 38 \\ weeks of age
}

\author{
VIEIRA, Danilo Vargas Gonçalves ${ }^{1 *}$; BARRETO, Sergio Luis Toledo de ${ }^{2}$; \\ VALERIANO, Matheus Henrique ${ }^{2}$; JESUS, Luiz Filipe Domeniche de ${ }^{2}$; SILVA, Luis \\ Felipe Fernandes $\mathrm{da}^{2}$; MENCALHA, Raquel ${ }^{2}$; BARBOSA, Keila Stefani ${ }^{2}$; MENDES, \\ Roberta Kely Viana ${ }^{2}$; CASSUCE, Meiry Rodrigues ${ }^{1}$; MELO, Thiago de Sousa ${ }^{1}$

\footnotetext{
${ }^{1}$ Universidade Federal da Paraíba, Centro de Ciências, Departamento de Zootecnia: Areia, Paraíba, Brasil. ${ }^{2}$ Universidade Federal de Viçosa, Centro de Ciências Agrárias, Departamento de Zootecnia, Viçosa, Minas Gerais, Brasil.

*Endereço para correspondência: ravenows@hotmail.com
}

\section{RESUMO}

Este experimento foi conduzido com objetivo de avaliar niveis de cálcio e fósforo disponível para codornas japonesas. Foram utilizadas 12 dietas e sete repetições de oito aves por repetição num total de 672 aves, as quais foram distribuídas segundo um delineamento inteiramente casualizado, em esquema fatorial, com três níveis de cálcio $(2,0 ; 2,5$ e $3,0 \%)$ e quatro de fósforo disponível $(0,10 ; 0,17$; 0,24 e $0,31 \%$ ). Observou-se interação significativa entre os níveis de cálcio e fósforo disponível para o consumo de ração e de cálcio, verificou-se efeito quadrático e linear para os níveis de fósforo disponível de codornas que consumiram dietas que continham 2,0 e 2,5\% de cálcio, respectivamente, e para dietas que continham $3,0 \%$ de cálcio não houve efeito significativo. A produção de ovos comerciais cresceu linearmente, influenciada pelo nível de fósforo disponível das dietas. Verificou-se interação significativa entre o cálcio e fósforo disponível, para os teores de fósforo e cinzas nas tíbias. Aumento dos níveis de fósforo disponível nas dietas proporcionou aumento do teor de fósforo nas tíbias das aves alimentadas com dietas que continham 3,0\% de cálcio e, efeito quadrático e linear sobre o teor de cinzas na tíbia das aves que receberam dietas com níveis 2,5 e 3,0\% de cálcio, respectivamente. Para o teor de cálcio nas tíbias, verificou-se aumento linear com elevação dos níveis de fósforo disponível nas dietas. O consumo de $555,4 \mathrm{mg}$ de cálcio $(2,0 \%)$ e de $88,18 \mathrm{mg}(0,31 \%)$ de fósforo disponível ave/dia, atende as exigências de codornas japonesas no período de 26 a 38 semanas de idade.

Palavras-chaves: avicultura, composição óssea, desempenho, qualidade da casca dos ovos

\section{SUMMARY}

This experiment was conducted to evaluate different levels of calcium and phosphorus available for Japanese quail. 12 diets were used and seven replications of eight birds per replicate for a total of 672 birds, which were distributed in a completely randomized in a factorial design, three levels of calcium $(2.0 ; 2.5$ and $3.0 \%)$ and four available phosphorus $(0.10 ; 0.17 ; 0.24$ and $0.31 \%)$. There was significant interaction between the levels of calcium and phosphorus available for feed intake and calcium, verifying linear and quadratic effect for the levels of available phosphorus of quail fed diets containing 2.0 and $2.5 \%$ calcium, respectively, for diets containing $3.0 \%$ calcium there was no significant effect. The commercial eggs production increased linearly influenced by the level of available phosphorus diets. Increased levels of available phosphorus in the diets, provided increase the phosphorus content in the tibia of birds fed with diets containing 3.0\% calcium, and linear and quadratic effect on the ash content in the tibia of birds fed diets containing 2.5 and $3.0 \%$ calcium, respectively. For the calcium content in the tibia, there was a linear increase with increasing levels of available phosphorus in the diet. The consumption of $555.4 \mathrm{mg}$ of calcium $(2.0 \%)$ and $88.18 \mathrm{mg}$ available phosphorus $(0.31 \%)$ bird/day, meets the requirements of Japanese quail of the 26 to 38 weeks of age.

Keywords: aviculture, bone composition, egg shell quality, performance 


\section{INTRODUÇ̃̃̃O}

Os minerais são considerados elementos essenciais para uma boa nutrição animal. De modo geral, os minerais estão envolvidos em quase todas as vias metabólicas, com funções na reprodução, metabolismo energético, entre outras (BERTECHINI, 2006).

Nas aves, o cálcio é um dos íons mais importantes do sistema ósseo, atua na regulação das contrações musculares, na transmissão do impulso nervoso, na coagulação sanguínea, na ativação de sistemas enzimáticos e na adesão celular, além da formação da casca do ovo, cuja participação é em $98 \%$ de sua composição (MACARI et al., 2002).

$\mathrm{O}$ fósforo, indicado como o mineral mais caro nas rações para monogástricos é objeto de muitas pesquisas devido à sua importância econômica, fisiológica e ambiental.

A qualidade da casca dos ovos pode ser influenciada por fatores de manejo, genéticos, ambientais, patológicos, fisiológicos (idades das aves), e nutricionais. Entre os vários fatores nutricionais que afetam a qualidade da casca do ovo, ressaltam-se os níveis de cálcio e fósforo provenientes da ração, pois a casca do ovo é constituída na sua quase totalidade por $\mathrm{CaCO}_{3}$.

Dentre os trabalhos publicados que abordam o estudo desses minerais, há controvérsias quanto à exigência de cálcio e fósforo em dietas para codornas em postura.

Barreto et al. (2007) concluíram que, para codornas japonesas na fase inicial de postura, níveis de $3,2 \%$ de cálcio na dieta, são ideais para obtenção de melhor produção e de eficiente conversão alimentar (por massa e por dúzia de ovos) e para manutenção da qualidade dos ovos. Garcia et al. (2000), encontraram que níveis de $2,5 \%$ de cálcio e $0,36 \%$ de Pd são ideais para melhor desempenho produtivo, melhor qualidade de casca e a maior resistência à quebra da tíbia. Já Costa et al. (2007) relataram que níveis $2,5 \%$ de cálcio e $0,31 \%$ de $\mathrm{Pd}$ são suficientes para proporcionar bom desempenho produtivo às codornas em inicio de postura.

Diante da importância do cálcio e do fósforo disponível, e de sua interação no organismo animal, objetivou-se neste trabalho avaliar o efeito de níveis de cálcio e de fósforo disponível nas dietas sobre o desempenho, a qualidade dos ovos e a deposição mineral na tíbia de codornas japonesas com idade de 26 a 38 semanas.

\section{MATERIAIS E MÉTODOS}

O experimento foi realizado no Departamento de Zootecnia do Centro de Ciências Agrárias da Universidade Federal de Viçosa, no período de setembro a dezembro de 2008.

Conduzido no delineamento inteiramente casualizado em esquema fatorial $(3 \times 4)$, três níveis de cálcio $(2,0 ; 2,5$ e $3,0 \%)$ e quatro de fósforo disponível $(0,10 ; 0,17$; 0,24 e $0,31 \%$ ), o experimento continha doze dietas, sete repetições e oito aves por repetição, em um total de 672 codornas japonesas.

As aves foram alojadas em gaiolas que continham quatro divisórias de $25 \times 34 \times 16 \mathrm{~cm}$, equipadas com comedouros tipo calha e bebedouros tipo "nipple". O programa de iluminação foi de 16 horas de luz diárias (4h às $20 \mathrm{~h}$ ), e o fornecimento de luz controlado por relógio automático (timer) que permitia o acender e o apagar das luzes durante $o$ período da noite e da madrugada.

A temperatura foi monitorada por termômetro de máxima e de mínima e a umidade relativa do ar verificada por 
Rev. Bras. Saúde Prod. Anim., Salvador, v.13, n.1, p.204-213 jan/mar, 2012 http://www.rbspa.ufba.br ISSN 15199940

termômetro de bulbo seco e bulbo úmido. A mensuração das temperaturas e umidade relativa do ar foi realizada duas vezes ao dia ( $8 \mathrm{~h}$ e às $16 \mathrm{~h}$ ), de modo que o termômetro de máxima e mínima era zerado apenas uma vez por dia, às $16 \mathrm{~h}$.

A ração basal (Tabela 1) fornecida foi formulada à base de milho e farelo de soja, com base em proteína ideal, para atender de forma completa as exigências nutricionais definidas pelo NRC (1994), exceto para os nutrientes estudados (cálcio e fósforo) e também para a energia metabolizável, aminoácidos digestíveis: lisina e metionina+cistina; treonina; e triptofano que foram definidos respectivamente por Moura et al. (2008),

Tabela 1. Composições percentual e calculada da ração basal (matéria natural)

\begin{tabular}{|c|c|}
\hline Ingrediente & Quantidade (kg) \\
\hline Milho & 56,41 \\
\hline Farelo de soja (45\%) & 32,33 \\
\hline Óleo de soja & 1,319 \\
\hline Sal & 0,321 \\
\hline L-lisina $(78,4 \%)$ & 0,174 \\
\hline DL-metionina $(99 \%)$ & 0,325 \\
\hline L-triptofano $(98 \%)$ & 0,011 \\
\hline L-isoleucina $(99 \%)$ & 0,207 \\
\hline L-arginina $(99 \%)$ & 0,177 \\
\hline L-valina $(99 \%)$ & 0,153 \\
\hline Cloreto de colina $(60 \%)$ & 0,100 \\
\hline Mistura vitamínica $^{1}$ & 0,100 \\
\hline Mistura mineral $^{2}$ & 0,050 \\
\hline Antioxidante $^{3}$ & 0,010 \\
\hline Fosfato bicálcio, calcário e inerte. & 8,313 \\
\hline Total & 100,00 \\
\hline \multicolumn{2}{|c|}{ Composição Calculada } \\
\hline Energia metabolizável (kcal/kg) & 2.800 \\
\hline Proteína bruta (\%) & 19,31 \\
\hline Cálcio & 2,000 \\
\hline Fósforo disponível & 0,100 \\
\hline Lisina digestível & 1,080 \\
\hline Metionina + cistina digestível & 0,864 \\
\hline Treonina digestível & 0,660 \\
\hline Triptofano digestível & 0,226 \\
\hline Valina total & 1,075 \\
\hline Isoleucina total & 1,052 \\
\hline Arginina total & 1,472 \\
\hline Leucina total & 1,659 \\
\hline Histidina total & 0,491 \\
\hline Fenilalanina + tirosina total & 1,636 \\
\hline \multicolumn{2}{|c|}{$\begin{array}{l}{ }^{1} \text { Composição/kg de produto: Vit. A: 12.000.000U.I., Vit D3: 3.600.000U.I., Vit. E: } 3.500 \text { U.I., Vit B1: } 2.500 \mathrm{mg} \text {, } \\
\text { Vit B2: } 8.000 \mathrm{mg} \text {, Vit B6: } 5.000 \mathrm{mg} \text {, Ácido pantotênico: 12.000mg, Biotina: 200mg, Vit. K: } 3.000 \mathrm{mg} \text {, Ácido fólico: } \\
1.500 \mathrm{mg} \text {, Ácido nicotínico: } 40.000 \mathrm{mg} \text {, Vit. B12: 20.000mg, Se: } 150 \mathrm{mg} \text {, Veículo q.s.p.: 1.000g. } \\
{ }^{2} \text { Composição/kg de produto: Mn: } 160 \mathrm{~g} \text {, Fe: } 100 \mathrm{~g} \text {, Zn: } 100 \mathrm{~g} \text { Co: } 20 \mathrm{~g} \text {, Co: } 2 \mathrm{~g} \text {, I: 2g, Excipiente q.s.p.: 1000g. } \\
{ }^{3} \text { Butil-hidróxi-tolueno. }\end{array}$} \\
\hline
\end{tabular}


Pinto et al. (2003a,b), Umigi et al. (2007) e Pinheiro et al. (2008). Os demais aminoácidos incluídos na dieta foram formulados com base total, mas corrigidos para a concentração de lisina total da ração basal, para manter a mesma relação proposta pelo NRC (1994).

As variáveis avaliadas foram: o consumo de ração $(\mathrm{g})$, consumo de cálcio $(\mathrm{mg})$, consumo de fósforo disponível (mg), a produção de ovos (\%/ave-dia e \%/avealojada), a produção de ovos comerciais (\%/ave-alojada), o peso do ovo (g), a massa de ovo (g/ave/dia), a conversão alimentar por dúzia de ovos $(\mathrm{kg} / \mathrm{dz})$ e, por massa de ovos $(\mathrm{kg} / \mathrm{kg})$, o peso de casca, gema e albúmen, o peso específico, e os teores de cálcio e fósforo e cinzas nas tíbias das codornas. Para estas três últimas variáveis foram sacrificadas duas aves por repetição e, utilizada a metodologia descrita por Silva \& Queiroz (2002) para determinação do cálcio e do fósforo nos ossos analisados (tíbias).

Foi verificada a normalidade dos erros e, posteriormente, os dados foram submetidos à análise de variância a 5\% de probabilidade mediante a utilização do programa SAEG (UFV, 2007). Em seguida, os efeitos dos níveis de cálcio e fósforo disponível foram estimados por meio de análise das variâncias pelos modelos de regressão linear e quadrática, conforme o melhor ajustamento obtido para cada variável.

\section{RESULTADOS E DISCUSSÃO}

$\mathrm{Na}$ fase adulta a faixa de conforto térmico das codornas está compreendida entre 18 e $22^{\circ} \mathrm{C}$, e a umidade relativa do ar está entre 65 e 70\% (OLIVEIRA, 2004).

Durante o experimento (Tabela 2) as temperaturas máximas estiveram acima do recomendado por Oliveira (2004), já a umidade relativa estava próxima do recomendado por este mesmo autor. Contudo, os animais não obtiveram perdas significativas nos parâmetros de desempenho, qualidade da casca de seus ovos e nos parâmetros ósseos, o que corrobora com os achados de Özbey et al. (2004) e, Özbey et al. (2006) nos quais esses autores observaram perda de desempenho a partir dos $30^{\circ} \mathrm{C}$.

Tabela 2. Temperaturas máximas, e mínimas, e umidades relativas médias (\%) registradas durante o período experimental

\begin{tabular}{cccc}
\hline \multirow{2}{*}{ Idade das aves (semanas) } & \multicolumn{2}{c}{ Temperatura $\left({ }^{\circ} \mathrm{C}\right)$} & \multirow{2}{*}{ UR $(\%)$} \\
\cline { 2 - 3 } & Máxima & Mínima & \\
\hline $26-29$ & 28,0 & 20,3 & 72 \\
$29-32$ & 29,1 & 20,4 & 69 \\
$32-35$ & 27,5 & 19,1 & 70 \\
$35-38$ & 27,6 & 20,3 & 71 \\
\hline
\end{tabular}

Ao se avaliar o consumo de codornas alimentadas com dietas que continham níveis de cálcio e fósforo disponível (Tabela 3), observou-se interação significativa dos níveis de cálcio $(2,0$;
$2,5$ e $3 \%)$ e fósforo disponível $(0,10$; 0,$17 ; 0,24$ e $0,31 \%$ ) apenas para o consumo de ração $(\mathrm{P}<0,01)$ e para $\mathrm{o}$ consumo de cálcio $(\mathrm{P}<0,05)$. 
Rev. Bras. Saúde Prod. Anim., Salvador, v.13, n.1, p.204-213 jan/mar, 2012 http://www.rbspa.ufba.br ISSN 15199940

O desdobramento da interação entre os níveis de cálcio $(2,0 ; 2,5$ e $3 \%)$ e fósforo disponível $(0,10 ; 0,17 ; 0,24 \mathrm{e}$ $0,31 \%$ ) para o consumo de ração e o consumo de cálcio, mostrou que codornas que consumiram dietas que continham $2,0 \%$ de cálcio, os níveis de fósforo disponível das dietas $(0,10$;
0,$17 ; 0,24$ e $0,31 \%$ ) influenciaram de forma quadrática $(\mathrm{P}<0,05)$ o consumo de ração e de cálcio, observado para consumo máximo, níveis $0,26 \%$ de fósforo disponível, o que correspondeu ao consumo diário de ração por ave de $28,8 \mathrm{~g}$ e, de $576,2 \mathrm{mg}$ de cálcio.

Tabela 3. Consumo de ração, cálcio e fósforo disponível de codornas japonesas

\begin{tabular}{|c|c|c|c|c|c|}
\hline \multirow{2}{*}{ Nível de cálcio (\%) } & \multicolumn{4}{|c|}{ Nível de fósforo disponível (\%) } & \multirow{2}{*}{ Médias } \\
\hline & 0,10 & 0,17 & 0,24 & 0,31 & \\
\hline \multicolumn{6}{|c|}{ Consumo de ração (g/ave/dia) ${ }^{1}$} \\
\hline $2,0^{2}$ & 25,77 & 28,26 & 28,38 & 28,66 & 27,47 \\
\hline $2,5^{3}$ & 27,55 & 27,77 & 27,90 & 28,82 & 27,74 \\
\hline $3,0^{\mathrm{ns}}$ & 27,89 & 27,01 & 27,91 & 27,86 & 27,60 \\
\hline Médias & 27,07 & 27,68 & 28,06 & 28,45 & $\mathrm{CV}=3,80$ \\
\hline \multicolumn{5}{|c|}{ Consumo de cálcio $(\mathrm{mg} / \mathrm{ave} / \mathrm{dia})^{4}$} & Médias \\
\hline $2,0^{5}$ & 515,4 & 565,2 & 567,7 & 573,2 & 555,4 \\
\hline $2,5^{6}$ & 688,7 & 694,3 & 697,5 & 720,6 & 700,3 \\
\hline $3,0^{\mathrm{ns}}$ & 836,7 & 810,0 & 837,2 & 835,7 & 829,9 \\
\hline Médias & 680,3 & 689,8 & 700,8 & 709,8 & $\mathrm{CV}=3,80$ \\
\hline & \multicolumn{4}{|c|}{ Consumo de fósforo $(\mathrm{mg} / \mathrm{ave} / \mathrm{dia})$} & Médias \\
\hline 2,0 & 25,77 & 48,04 & 68,12 & 88,85 & 57,70 \\
\hline 2,5 & 27,55 & 47,21 & 66,96 & 89,35 & 57,77 \\
\hline 3,0 & 27,89 & 45,92 & 66,98 & 86,35 & 56,79 \\
\hline Médias $^{7}$ & 27,07 & 47,06 & 67,35 & 88,18 & $\mathrm{CV}=3,88$ \\
\hline
\end{tabular}

${ }^{1}$ Interação significativa $(\mathrm{P}<0,01) ;{ }^{2}$ Efeito quadrático $(\mathrm{P}<0,05): \mathrm{Y}=21,1397+58,8550 \mathrm{X}-112,888 \mathrm{X}^{2}$; $\mathrm{R}^{2}=0,94 ;{ }^{3}$ Efeito linear $(\mathrm{P}<0,05)$ : $\mathrm{Y}=26,8512+5,65451 \mathrm{X} ; \mathrm{R}^{2}=0,83 ;{ }^{4}$ Interação significativa $(\mathrm{P}<0,05)$; ${ }^{5}$ Efeito quadrático $(\mathrm{P}<0,05)$ : $\mathrm{Y}=422,794+1177,10 \mathrm{X}-2257,76 \mathrm{X}^{2} ; \mathrm{R}^{2}=0,94 ;{ }^{6}$ Efeito linear $(\mathrm{P}<0,05)$ : $\mathrm{Y}=671,281+141,363 \mathrm{X} ; \mathrm{R}^{2}=0,83 ;{ }^{7}$ Efeito linear $(\mathrm{P}<0,01): \mathrm{Y}=-2,22163+290,919 \mathrm{X} ; \mathrm{R}^{2}=0,99 ;{ }^{\text {ns }}$ Nãosignificativo $(\mathrm{P}>0,05)$.

$\mathrm{CV}=$ coeficiente de variação (\%).

Nas dietas que continham $2,5 \%$ de cálcio houve efeito linear $(\mathrm{P}<0,05)$ crescente dos níveis de fósforo disponível $(0,10 ; 0,17 ; 0,24$ e $0,31 \%)$ sobre o consumo de ração e de cálcio. A observação do aumento do consumo de cálcio pelas codornas em dietas com 2,0 e $2,5 \%$ de cálcio é devido ao melhor ajustamento da relação entre esses dois minerais, que ficou em torno de 7,69 e 8,06 respectivamente. Já naquelas com $3,0 \%$, os níveis de cálcio possivelmente estavam acima da relação, uma vez que não afetaram o consumo de cálcio em função do nível de fósforo da dieta.

Esses resultados discordam daqueles observados por Garcia et al. (2000) que ao trabalharem com dietas que continham quatro níveis de cálcio $(2,5$; 3,$0 ; 3,5$ e $4,0 \%$ ) e de fósforo disponível $(0,27 ; 0,32 ; 0,37$ e $0,42 \%)$ e por Costa et al. (2007) quando trabalharam com dietas que continham dois níveis de cálcio $(2,5$ e $3,2 \%)$ e cinco de fósforo 
disponível $(0,15 ; 0,25 ; 0,35 ; 0,45 \mathrm{e}$ $0,55 \%$ ), que não encontraram interação significativa para o consumo de ração de codornas japonesas em postura.

Não foi detectada interação significativa entre os níveis de cálcio e fósforo empregados nas dietas sobre o consumo de fósforo. Observou-se efeito linear $(\mathrm{P}<0,01)$ para consumo de fósforo em função do aumento dos níveis de fósforo disponível $(0,10 ; 0,17 ; 0,24 \mathrm{e}$ $0,31 \%$ ) nas dietas. Na medida em que, aumentaram-se os níveis de fósforo disponível nas dietas, observou-se aumento de $5,1 \%$ no consumo diário de fósforo pelas aves.

Os parâmetros avaliados (Tabela 4), não foram influenciados pela interação cálcio e fósforo $(\mathrm{P}>0,05)$. Esses resultados concordam com aqueles encontrados por Costa et al. (2007) que ao trabalharem com dietas que continham dois níveis de cálcio $(2,5$ e $3,2 \%)$ e cinco de fósforo disponível $(0,15 ; 0,25 ; 0,35 ; 0,45 \quad \mathrm{e}$ $0,55 \%)$ também não encontraram efeito de interação cálcio e fósforo.

Tabela 4. Desempenho e qualidade de ovos de codornas japonesas alimentadas com dietas contendo diferentes níveis de cálcio

\begin{tabular}{|c|c|c|c|c|c|}
\hline \multirow{2}{*}{ Item } & \multicolumn{4}{|c|}{ Nível de cálcio (\%) } & \multirow{2}{*}{ Efeito } \\
\hline & 2,0 & 2,5 & 3,0 & $\mathrm{CV}$ & \\
\hline Produção de ovos (ave-dia) & 91,77 & 92,28 & 92,03 & 4,09 & $\mathrm{~ns}$ \\
\hline Produção de ovos (ave-alojada) & 85,67 & 86,19 & 84,44 & 8,17 & ns \\
\hline Ovos comerciais (ave-alojada) & 89,18 & 89,90 & 89,41 & 4,93 & ns \\
\hline Peso dos ovos $(\mathrm{g})$ & 12,16 & 12,16 & 12,16 & 2,05 & ns \\
\hline Massa de ovos (g/ave/dia) & 11,15 & 11,19 & 11,28 & 4,55 & ns \\
\hline Conversão alimentar (kg/dz) & 0,360 & 0,362 & 0,361 & 4,86 & $\mathrm{~ns}$ \\
\hline Conversão alimentar (kg/kg) & 3,97 & 3,96 & 4,04 & 10,60 & ns \\
\hline Viabilidade (\%) & 84,52 & 86,31 & 85,12 & 15,59 & ns \\
\hline Peso de casca $(\mathrm{g})^{1}$ & 1,01 & 1,03 & 1,05 & 3,33 & $\mathrm{P}<0,01$ \\
\hline Peso de gema $(g)^{2}$ & 3,73 & 3,73 & 3,65 & 2,40 & $\mathrm{P}<0,05$ \\
\hline Peso de albúmen (g) & 7,42 & 7,42 & 7,46 & 2,75 & ns \\
\hline Peso específico $\left(\mathrm{g} / \mathrm{cm}^{3}\right)^{3}$ & 1,071 & 1,073 & 1,074 & 0,220 & $\mathrm{P}<0,01$ \\
\hline
\end{tabular}

Os níveis de cálcio $(2,0 ; 2,5$ e $3,0 \%)$ da dieta não influenciaram $(\mathrm{P}>0,05)$ a produção de ovos (ave/dia e ave/alojada), ovos comerciais, peso dos ovos, massa de ovos, conversão alimentar $(\mathrm{kg} / \mathrm{kg}$ e $\mathrm{kg} / \mathrm{dz}$ ), viabilidade e peso de albúmen. Estes resultados corroboram os encontrados por Costa et al. (2007) quando avaliaram dois níveis de cálcio (2,5 e 3,2\%). Entretanto, discordam dos achados de Yakout et al. (2004) ao testarem três níveis de cálcio $(2,0 ; 2,5$ e
$3,0 \%$ ) e de Brandão et al. (2007) ao estudarem sete níveis de cálcio $(2,95$; $3,10 ; 3,25 ; 3,40 ; 3,55 ; 3,70$ e $3,85 \%)$, que observaram efeito significativo dos níveis de cálcio da dieta, sobre a produção e o peso dos ovos. Os resultados encontrados por Barreto et al. (2007), discordam para os parâmetros, produção de ovos e peso dos ovos que foram influenciados linearmente, e para massa de ovos que foi afetada de forma quadrática pelos níveis de cálcio 
$(1,6 ; 2,0 ; 2,4 ; 2,8 ; 3,2 ;$ e $3,6 \%)$ das dietas. O aumento dos níveis de cálcio $(2,0 ; 2,5$ e $3,0 \%)$ da dieta elevou linearmente o peso de casca $(\mathrm{P}<0,01)$, diminui, linearmente o peso de gema $(\mathrm{P}<0,05)$ e melhorou o peso específico $(\mathrm{P}<0,05)$ dos ovos. Estes resultados discordam com aqueles encontrados por Brandão et al. (2007), que ao avaliarem níveis crescentes de cálcio de 2,95 a $3,55 \%$, observaram melhora no peso de gema. Embora tenha sido observada redução no peso de gema (Tabela 4), não se verificou diferença significativa no peso dos ovos (Tabela 4) para todos os níveis de cálcio $(2,0 ; 2,5$ e 3,0\%) estudados.

Estes resultados corroboram os encontrados por Barreto et al. (2007) que observaram efeito quadrático, o que indica ser o nível de $3,42 \%$ de cálcio o que proporcionou maior peso de casca ao avaliarem dietas que continham níveis crescentes de cálcio (1,6 a 3,6\%) para codornas japonesas em postura. No entanto, contradizem os resultados encontrados por Costa et al. (2007), que não verificaram diferença significativa para o peso de gema e de casca, mas observaram melhora na qualidade da casca em função dos níveis de cálcio de $(2,5$ e $3,2 \%)$ das dietas.

Os níveis de fósforo disponível $(0,10$; $0,17 ; 0,24$ e $0,31 \%)$ da dieta não influenciaram $(\mathrm{P}>0,05)$ a produção de ovos (ave-dia e ave-alojada), o peso dos ovos, a massa de ovos, e conversão alimentar $(\mathrm{kg} / \mathrm{kg}$ e $\mathrm{kg} / \mathrm{dz})$, peso de casca, viabilidade e peso de albúmen. Estes resultados corroboram os encontrados por Costa et al. (2007), exceto para a conversão alimentar $(\mathrm{kg} / \mathrm{dz})$ uma vez que os níveis de fósforo disponível $(0,15 ; 0,25 ; 0,35$; 0,45 e $0,55 \%$ ) das dietas afetaram de forma linear esse parâmetro.

O aumento dos níveis de fósforo disponível na dieta (Tabela 5) promoveu melhoria $(\mathrm{P}<0,05)$ na produção de ovos comerciais. Estes resultados concordam com aqueles verificados por Costa et al. (2007) ao avaliarem os níveis $(0,15 ; 0,25 ; 0,35$; 0,45 e $0,55 \%$ ) de fósforo disponível.

Tabela 5. Desempenho e qualidade de ovos de codornas japonesas alimentadas com dietas contendo diferentes níveis de fósforo disponível

\begin{tabular}{|c|c|c|c|c|c|c|}
\hline \multirow{2}{*}{ Item } & \multicolumn{5}{|c|}{ Nível de fósforo disponível (\%) } & \multirow{2}{*}{ Efeito } \\
\hline & 0,10 & 0,17 & 0,24 & 0,31 & $\mathrm{CV}$ & \\
\hline Produção de ovos (ave-dia) & 91,67 & 92,47 & 91,94 & 94,19 & 4,09 & ns \\
\hline Produção de ovos (ave-alojada) & 83,39 & 89,07 & 83,85 & 89,19 & 8,17 & ns \\
\hline Ovos comerciais (ave-alojada) ${ }^{1}$ & 88,80 & 89,67 & 90,02 & 92,58 & 4,93 & $\mathrm{P}<0,05$ \\
\hline Peso dos ovos $(\mathrm{g})$ & 12,21 & 12,18 & 12,10 & 12,16 & 2,05 & ns \\
\hline Massa de ovos (g/ave/dia) & 11,35 & 11,22 & 11,40 & 11,32 & 4,55 & $\mathrm{~ns}$ \\
\hline Conversão alimentar (kg/dz) & 0,355 & 0,360 & 0,367 & 0,363 & 4,86 & ns \\
\hline Convesão alimentar (kg/kg) & 3,98 & 3,87 & 4,16 & 3,95 & 10,60 & $\mathrm{~ns}$ \\
\hline Viabilidade (\%) & 83,33 & 89,88 & 82,74 & 88,69 & 15,59 & ns \\
\hline Peso de casca (g) & 1,03 & 1,04 & 1,03 & 1,02 & 3,33 & ns \\
\hline Peso de gema (g) & 3,77 & 3,68 & 3,66 & 3,69 & 2,40 & ns \\
\hline Peso de albúmen (g) & 7,42 & 7,47 & 7,45 & 7,49 & 2,75 & ns \\
\hline Peso específico $\left(\mathrm{g} / \mathrm{cm}^{3}\right)^{2}$ & 1,073 & 1,072 & 1,072 & 1,071 & 0,220 & $\mathrm{P}<0,05$ \\
\hline
\end{tabular}


Rev. Bras. Saúde Prod. Anim., Salvador, v.13, n.1, p.204-213 jan/mar, 2012 http://www.rbspa.ufba.br ISSN 15199940

Embora se observe melhoria dos ovos comerciais com aumento dos níveis de fósforo disponível nas dietas, os mesmos níveis $(0,10 ; 0,17 ; 0,24 \mathrm{e}$ $0,31 \%$ ) influenciaram de forma negativa o parâmetro de qualidade de casca: o peso específico (Tabela 5). Contudo, os níveis de cálcio $(2,0 ; 2,5$ e $3,0 \%)$ das dietas melhoram esse parâmetro de forma linear (Tabela 4), o que demonstra que o cálcio dietético é mais importante para melhoria da qualidade da casca do que o fósforo, uma vez que o mesmo participa em menor parte na formação da casca.

Para os parâmetros ósseos de codornas japonesas (Tabela 6), verificou-se interação significativa $(\mathrm{P}<0,01)$ entre os fatores estudados apenas para os teores de fósforo e cinzas nas tíbias. Estes resultados discordam dos encontrados por Garcia et al. (2000), que verificaram que não houve interação significativa dos níveis de cálcio e fósforo disponíveis estudados sobre os paramentos ósseos das codornas.

O desdobramento dos níveis de fósforo disponível $(0,10 ; 0,17 ; 0,24$ e $0,31 \%)$ dentro dos de cálcio $(2,0 ; 2,5$ e $3,0 \%)$ permitiu observar que houve efeito linear $(\mathrm{P}<0,05)$ dos níveis de fósforo disponível nas dietas com $3,0 \%$ de cálcio para o teor de cálcio na tíbia das aves, e efeito não significativo $(\mathrm{P}>0,05)$ em dietas que continham 2,0 e $2,5 \%$ de cálcio.

Tabela 6. Percentagem de cálcio, fósforo e de cinzas na tíbia de codornas japonesas

\begin{tabular}{|c|c|c|c|c|c|}
\hline \multirow{2}{*}{ Nível de Ca (\%) } & \multicolumn{4}{|c|}{ Nível de fósforo disponível (\%) } & \multirow[b]{2}{*}{ Médias } \\
\hline & 0,10 & 0,17 & 0,24 & 0,31 & \\
\hline \multicolumn{6}{|c|}{ Percentagem de cálcio (\%) } \\
\hline 2,0 & 18,36 & 19,59 & 18,49 & 22,67 & 18,81 \\
\hline 2,5 & 21,72 & 19,64 & 18,15 & 21,28 & 19,84 \\
\hline 3,0 & 16,80 & 20,80 & 20,67 & 22,48 & 19,42 \\
\hline Médias ${ }^{1}$ & 18,96 & 20,01 & 19,10 & 22,14 & $\mathrm{CV}=14,10$ \\
\hline \multicolumn{5}{|c|}{ Percentagem de fósforo $(\%)^{2}$} & Médias \\
\hline $2,0^{\mathrm{ns}}$ & 9,38 & 8,92 & 9,42 & 9,55 & 9,24 \\
\hline $2,5^{\mathrm{ns}}$ & 8,55 & 9,14 & 7,93 & 9,65 & 8,54 \\
\hline $3,0^{3}$ & 8,36 & 8,83 & 9,32 & 9,15 & 8,84 \\
\hline Médias & 8,76 & 8,96 & 8,89 & 9,45 & $\mathrm{CV}=5,38$ \\
\hline \multicolumn{5}{|c|}{ Percentagem de cinza $(\%)^{2}$} & Médias \\
\hline $2,0^{\mathrm{ns}}$ & 49,01 & 46,31 & 47,40 & 48,70 & 47,57 \\
\hline $2,5^{4}$ & 43,70 & 45,26 & 44,43 & 49,71 & 44,46 \\
\hline $3,0^{5}$ & 44,39 & 44,25 & 49,41 & 47,29 & 46,02 \\
\hline Médias & 45,70 & 45,27 & 47,08 & 48,57 & $\mathrm{CV}=3,76$ \\
\hline
\end{tabular}

As tíbias provenientes de aves que receberam dieta que continha $3,0 \%$ de cálcio aumentaram em $9,4 \%$ o teor de fósforo em relação às dietas com 0 menor e o maior nível de fósforo disponível. Estes resultados concordam 
Rev. Bras. Saúde Prod. Anim., Salvador, v.13, n.1, p.204-213 jan/mar, 2012 http://www.rbspa.ufba.br ISSN 15199940

parcialmente com Costa et al. (2007), que ao avaliarem dietas que continham níveis de cálcio e fósforo disponível, encontraram efeito dos níveis de fósforo $(0,10 ; 0,17 ; 0,24$ e $0,31 \%)$ das dietas para o teor de fósforo nas tíbias em ambos os níveis de cálcio estudados $(2,0 ; 2,5$ e $3,0 \%)$.

Para o teor de cinzas na tíbia, observouse comportamento quadrático e linear $(\mathrm{P}<0,01)$ em função do aumento dos níveis de fósforo disponível $(0,10 ; 0,17$; 0,24 e $0,31 \%$ ) em dietas que continham 2,5 e $3,0 \%$ de cálcio, respectivamente. Menor teor de cinzas foi obtido nos ossos da tíbia de aves que receberam dieta com $0,14 \%$ de fósforo disponível quando se utilizou dieta com $2,5 \%$ de cálcio. E quando se utilizou dieta com $3,0 \%$ de cálcio, o teor de cinzas aumentou em $6,8 \%$ ao compararem àqueles obtidos com o fornecimento da dieta que continha o menor e o maior nível de fósforo disponível.

Para os teores de cálcio nas tíbias, houve aumento linear $(\mathrm{P}<0,05) \mathrm{em}$ função dos níveis de fósforo disponível utilizados. No entanto, os níveis de cálcio da dieta não influenciaram $(\mathrm{P}>0,05)$ o teor de cálcio das tíbias, estes resultados corroboram os encontrados por Raju et al. (1992), nos quais não foram verificados efeitos dos níveis de cálcio das dietas utilizadas, nos teores de cálcio presente nas tíbias.

A menor recomendação de cálcio $(2,0 \%)$ contribui para menor excreção desse mineral para o meio ambiente, e consequentemente diminuição da poluição. Níveis mais altos de fósforo disponível são recomendados para melhor qualidade da casca dos ovos. Ingestão diária de 555,4mg de cálcio e $88,18 \mathrm{mg}$ de fósforo disponível por ave, o que atende as exigências desses minerais para obtenção satisfatória do desempenho e da qualidade de ovos de codornas japonesas no período de 26 a 38 semanas de idade é recomendada.

\section{REFERÊNCIAS}

BARRETO, S.L.T.; PEREIRA, C.A.; UMIGI, R.T.; ROCHA, T.C.; ARAUJO, M.S.; SILVA, C.S.; TORRES FILHO, R.A. Determinação da exigência nutricional de cálcio de codornas japonesas na fase inicial do ciclo de produção. Revista Brasileira de Zootecnian v.36, n.1, p.68-78, 2007.

BERTECHINI, A.G. Nutrição de monogástricos. Lavras: Universidade Federal de Lavras, 2006, 301p.

BRANDÃO, P.A.; COSTA, F.G.P.; SILVA, J.H.V.; BRANDÃO, J.S.; NOBRE, J.G.S.; GOULART, C.C. Exigência de cálcio para codornas japonesas (Coturnix coturnix japonica) em postura. Acta Scientiarum Animal Sciences, v.29, n.1, p.17-21, 2007.

COSTA, C.H.R.; BARRETO, S.L.T.; MOURA, W.C.O.; REIS, R.S.; LEITE, C.D.S.; MAIA, G.V. Níveis de fósforo e de cálcio em dietas para codornas japonesas em postura. Revista Brasileira de Zootecnia, v.36, p.20372046, 2007.

GARCIA. J.; MURAKAMI, A.E.; MARTINS, E.N.; FURLAN, A.C. Exigências nutricionais de cálcio e fósforo para codornas japonesas (Coturnix coturnix japonica) em postura. Acta Scientiarum, v.22, n.3, p.733-739, 2000.

MACARI, M.; FURLAN, L.R.; GONZALES, E. Fisiologia aviária aplicada a frangos de corte. Jaboticabal: FUNEP/UNESP, 2002. $375 p$. 
Rev. Bras. Saúde Prod. Anim., Salvador, v.13, n.1, p.204-213 jan/mar, 2012 http://www.rbspa.ufba.br ISSN 15199940

MOURA, G.S.; BARRETO, S.L.T.; DONZELE, J.L.; HOSODA, L.R.; PENA, G.M.; ANGELINI, M.S. Dietas de diferentes densidades energéticas mantendo constante a relação energia metabolizável: nutrientes para codornas japonesas em postura. Revista

Brasileira de Zootecnia, v.37, n.9, p.1628-1633, 2008.

\section{NATIONAL RESEARCH COUNCIL -} NRC. Nutrient requirements of poultry. 9th revised ed. Washington, D. C.: National Academy Press, 1994.

OLIVEIRA, B.L. Importância do manejo na produção de ovos de codornas. In: SIMPÓSIO

INTERNACIONAL DE COTURNICULTURA, 2., 2004, Lavras. Anais... Lavras: Núcleo de Estudos em Ciência e Tecnologia Avícolas, 2004. p.91-96.

ÖZBEY, O.; ERISIR, Z.; AYSÖNDÜ, M.H.; ÖZMEN, Ö. The effect of high temperatures on breeding and survival of japanese quails that are bred under different temperatures. International Journal of Poultry Science, v.3, n.7, p.463-467, 2004.

ÖZBEY, O.; YILDIZ, N.; ESEN, F. The Effects of High Temperature on Breeding Characteristics and the Living Strength of the Japanese Quails (Coturnix Coturnix Japonica). International Journal of Poultry Science, v.5, n.1, p.56-59, 2006.

PINHEIRO, S.R.F.; BARRETO, S.L.T.; ALBINO, L.F.T; ROSTAGNO, H.S.; UMIGI, R.T.; BRITO, C.O. Efeito dos níveis de triptofano digestível em dietas para codornas japonesas em postura. Revista Brasileira Zootecnia, v.37, n.6, p.1012-1016, 2008.
PINTO, R.; FERREIRA, A.S.; DONZELE, J.L.; SILVA, M.A.; SOARES, R.T.R.N.; CUSTÓDIO, G.S.; PENA, K.S. Exigência de lisina para codornas japonesas em postura. Revista Brasileira de Zootecnia, v.32, n.5, p.1182-1189, 2003a.

PINTO, R.; DONZELE, J.L.; FERREIRA, A.S.; ALBINO, L.F.T.; SILVA, M.A.; SOARES, R.T.N.; PEREIRA, C.A. Exigência de metionina mais cistina para codornas japonesas em postura. Revista Brasileira de Zootecnia, v.32, n.5, p.1166-1173, 2003b.

RAJU, M.V.L.N.; RAO, P.V.; REDDY, V.R. Effect of dietary calcium and inorganic phosphorus on the performance of laying Coturnix quail. Indian Journal of Animal Science, v.62, p.1072-1076, 1992.

SILVA, D.J.; QUEIROZ, A.C. Análises de alimentos: métodos químicos $\mathrm{e}$ biológicos. 3.ed. Viçosa, MG: Universidade Federal de Viçosa, 2002. $235 \mathrm{p}$.

UMIGI, R.T.; BARRETO, S.L.T.; DONZELLE, J.L.; REIS, R.S.; SOUSA, M.F.; LEITE, C.D.S. Níveis de treonina digestível em dietas para codorna japonesa em postura. Revista Brasileira de Zootecnia, v.36, n.6, p.1868-1874, 2007.

UNIVERSIDADE FEDERAL DE VIÇOSA - UFV. SAEG - Sistema para Análises Estatísticas. Versão 9.1. Viçosa, MG, 2007.

YAKOUT, H.M. Calcium and phosphorus requirements of Japanese quail hens during the early production period.

Egyptian Poultry Science Journal, v.23, p.617-628, 2004.

Data de recebimento: 19/08/2011

Data de aprovação: 09/02/2012 